\title{
GSK-3 $\beta$ may be involved in hippocampal mossy fiber sprouting in the pentylenetetrazole-kindling model
}

\author{
WEN-JIAO HUANG ${ }^{1}$, FA-FA TIAN ${ }^{1}$, JIN-MEI CHEN ${ }^{2}$, TING-HUI GUO ${ }^{3}$, \\ YUN-FENG MA ${ }^{4}$, JIA FANG ${ }^{5}$, JING DANG ${ }^{1}$ and MING-YU SONG ${ }^{1}$ \\ ${ }^{1}$ Department of Neurology, Xiangya Hospital, Central South University, Changsha, Hunan 410008; \\ ${ }^{2}$ Department of Neurology, Putuo Hospital of Shanghai, Shanghai 200062; ${ }^{3}$ Department of Neurology, Zhangzhou Hospital, \\ Fujian Medical University, Zhangzhou, Fujian 363000; ${ }^{4}$ Department of Neurology, Sanbofuxing Brain Hospital, \\ Beijing 100038; ${ }^{5}$ Department of Neurology, 1st People's Hospital of Zhengzhou, Zhengzhou, Henan 450004, P.R. China
}

Received March 6, 2013; Accepted August 16, 2013

DOI: $10.3892 / \mathrm{mmr} .2013 .1660$

\begin{abstract}
Mossy fiber sprouting (MFS) is a pathological phenomenon that is commonly observed in temporal lobe epilepsy (TLE). However, the molecular mechanisms underlying MFS remain unclear. It has been demonstrated that the tau protein is important in the progression of MFS by the regulation of microtubule dynamics and axonal transport, with all of these functions of tau modulated by its site-specific phosphorylation. Glycogen synthase kinase-3 $\beta$ (GSK-3 $\beta$ ) is an active kinase that regulates the phosphorylation of tau protein. Therefore, it was hypothesized that GSK-3 $\beta$ contributes to MFS by phosphorylating tau protein. The aim of the present study was to determine the expression and activity of GSK-3 $\beta$ at different regions in the rat hippocampus during the pentylenetetrazole (PTZ)-kindling process in order to demonstrate the possible correlation with MFS, and to investigate the involvement of GSK-3 $\beta$ in epileptogenesis. Male Sprague-Dawley rats $(n=180)$ were randomly divided into the control and PTZ-treated groups. The chronic epileptic model was established by intraperitoneal injection of PTZ and the hippocampus was observed for the presence of MFS using Timm staining. GSK-3 $\beta$ mRNA, protein and activity were analyzed in various regions of the hippocampus using in situ hybridization, immunohistochemistry and immunoprecipitation followed by a kinase assay and liquid scintillation counting, respectively. MFS was observed prior to kindling and an increased distribution of Timm granules were observed in the CA3 region of the PTZ-treated rats; however, this was not demonstrated in the supragranular layer of the dentate
\end{abstract}

Correspondence to: Professor Fa-Fa Tian, Department of Neurology, Xiangya Hospital, Central South University, 87 Xiangya Road, Changsha, Hunan 410008, P.R. China

E-mail: tianfafa@outlook.com

Key words: pentylenetetrazole, glycogen synthase kinase-3 $\beta$, tau protein, mossy fiber sprouting, hippocampus, temporal lobe epilepsy gyrus. The expression of GSK-3 $\beta$ mRNA and protein, as well as the GSK-3 $\beta$ activity, increased significantly from 3 days to 4 weeks in the PTZ group, and this was correlated with the progression of MFS in the CA3 area. In addition, it was demonstrated that MFS did not result from TLE. GSK-3 $\beta$ may therefore be involved in the progression of MFS and is important in epileptogenesis. An understanding of the molecular mechanisms underlying MFS may lead to the identification of a novel therapeutic target to limit epileptogenesis.

\section{Introduction}

Mossy fiber sprouting (MFS) has been observed in experimental models of temporal lobe epilepsy (TLE) (1) and in the epileptic human hippocampus (2), and the involvement of MFS in TLE has long been demonstrated. Previous studies have supported the hypothesis that MFS alters synaptic connectivity and circuit organization, thus forming recurrent excitatory connections, which contribute to an enhanced susceptibility to seizures (3). However, other studies have demonstrated that MFS is a consequence of TLE, an event that is not correlated with seizures (4). Therefore, the mechanisms underlying MFS remain unclear and the sequence of occurrence of MFS and TLE is controversial.

Tau protein is an important microtubule-associated protein that is localized in neuronal axons and facilitates microtubule dynamics, axonal transport, neurite outgrowth and axonal elongation (5). These functions of tau are modulated by site-specific phosphorylation, mainly occurring at Ser202/Thr205 (6). Furthermore, various epilepsy models have confirmed the significantly increased phosphorylation of tau protein following seizure, and the resulting induced MFS is important in TLE $(7,8)$. Although different kinases may modify tau, it has been suggested that glycogen synthase kinase-3 $\beta$ (GSK-3 $\beta$ ) is important in regulating tau phosphorylation, including at the Ser202/Thr205 residue, under physiological and pathological conditions (9).

GSK-3 $\beta$ is a constitutively active multi-functional serine/threonine kinase that is involved in regulating diverse physiological pathways, including neuronal structure, apoptosis, axon growth and guidance, cytoskeletal stability and 
synaptic plasticity (10). Furthermore, previous studies have demonstrated that GSK-3 $\beta$ affects axoplasmic transport and axonal growth through the phosphorylation of tau protein (11). Therefore, GSK-3 $\beta$ may also function in epileptogenesis, particularly in MFS by a mechanism involving tau phosphorylation. In the present study, the progression of MFS was observed during kindling in association with the expression levels of GSK-3 $\beta$ mRNA and protein, and with GSK-3 $\beta$ activity, in order to investigate the correlation between TLE, MFS and GSK-3 $\beta$ and the involvement of GSK-3 $\beta$ in epileptogenesis.

\section{Materials and methods}

Animal groupings. Male Sprague-Dawley (SD) rats $(\mathrm{n}=180$; age, 6-8 weeks; weight, 180-120 g) obtained from the Animal Experimental Centre (Central South University, Chengsha, China) were divided into the control and PTZ groups by the random number method. The study was conducted in accordance with the guidelines of the Central South University and the Guide for the Care and Use of Laboratory Animals (12), and was approved by the Institutional Animal Care and Use Committee of Central South University. All efforts were made to minimize animal suffering and to reduce the number of animals used in each group. The groups were further divided into five subgroups, each containing 18 rats, which were sacrificed at different time points (3 days and 1, 2, 4 and 6 weeks) following the initial PTZ injection (Sigma-Aldrich, St. Louis, MO, USA). Rats of the five subgroups were sacrificed and perfused for Timm staining and scoring, immunohistochemistry and in situ hybridization of GSK-3 $\beta$ and GSK-3 $\beta$ kinase activity.

Animal models and behavior monitoring. Rats in the PTZ group received one dose of $30 \mathrm{mg} / \mathrm{kg}$ PTZ intraperitoneally (i.p.) daily until they were kindled or sacrificed. The control rats were injected with an equal dose of saline. Rats were observed every $2 \mathrm{~h}$ daily for the occurrence of PTZ-induced seizures prior to kindling. Convulsive behavior was classified into five stages as proposed by Racine (13). Rats were considered to be kindled when a seizure attack (score, $\geq 3$ ) occurred following each PTZ injection for five consecutive days. Seizure activity in kindled rats without PTZ induction was perceived as spontaneous recurrent seizures (SRSs). Kindled rats were monitored for seizure occurrence using a video camera positioned above the cages until they were sacrificed.

Timm staining. At the aforementioned time points, rats were sacrificed $(n=60)$. The rats were anesthetized with $10 \%$ chloral hydrate and intracardially perfused with $150 \mathrm{ml}$ saline, followed by $200 \mathrm{ml} 0.1 \mathrm{~mol} / 1$ phosphate buffer ( $\mathrm{pH} \mathrm{7.2-7.6)}$ containing $0.4 \%$ sodium sulfide and $250 \mathrm{ml} 4 \%$ paraformaldehyde at $4^{\circ} \mathrm{C}$. The brains were carefully removed and fixed in $4 \%$ paraformaldehyde for $24 \mathrm{~h}$. Subsequent to this, the brains were transferred into $0.1 \mathrm{~mol} / 1$ phosphate buffer containing $30 \%$ sucrose at $4^{\circ} \mathrm{C}$ until they sank for $72 \mathrm{~h}$, following which they were embedded in OCT and stored at $-70^{\circ} \mathrm{C}$ for further analysis. The embedded brains were cut into $25-\mu \mathrm{m}$ coronal sections using a vibratome (CM1950; Leica, Wetzlar, Germany) and the microscope slides with brain slices were placed into a
Timm developer (MaxQ7000; Thermo Scientific, Waltham, MA, USA) for $60-80 \mathrm{~min}$ at $26^{\circ} \mathrm{C}$ in the dark and then removed for a 5-min wash in water to terminate the reaction. The slides were dehydrated, cleaned and mounted with gum consisting of

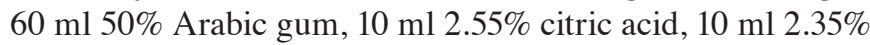
sodium citrate, $30 \mathrm{ml} 5.67 \%$ hydroquinone and $1.5 \mathrm{ml} 17 \%$ silver nitrate. The distribution of Timm granules in the dentate gyrus (DG) supragranular regions and the stratum oriens of CA3 was rated on a scale of 0 to 5 according to previously described criteria (14).

Immunohistochemistry and in situ hybridization. Rats $(\mathrm{n}=60)$ were anesthetized with $10 \%$ chloral hydrate (i.p.) and perfused intracardially with saline and $4 \%$ paraformaldehyde. The brains were removed and coronally divided into two sections, $3.5 \mathrm{~mm}$ posterior to the bregma. The anterior section was placed in $4 \%$ paraformaldehyde overnight for immunohistochemistry, while the posterior section was placed in $4 \%$ paraformaldehyde with $0.1 \%$ diethylpyrocarbonate for $30 \mathrm{~min}$, for in situ hybridization. Subsequent to this, tissues were sliced, routinely processed and embedded in paraffin wax. Serial sections were cut at $5-\mu \mathrm{m}$ thickness. Immunohistochemistry was performed using the SABC method (polyclonal antibody against GSK-3 $\beta$; Boster Biological Tech Ltd., Fremont, CA, USA). In situ hybridization was conducted using the in situ hybridization kit (MK1750; Boster, Wuhan, China) according to the manufacturer's instructions. The gray value was measured and analyzed using the image analysis system HPIAS-1000 (Championimages, Wuhan, China).

GSK-3 $\beta$ activity assay. Rabbit monoclonal anti-GSK-3 $\beta$ antibody ( $2 \mu \mathrm{g} /$ reaction; Abcam, Cambridge, MA, USA) was added to rat brain tissue lysate (hippocampus and frontal region) and incubated for $1 \mathrm{~h}$ with gentle agitation. Protein G-agarose (40 $\mu \mathrm{l}$; Sigma-Aldrich) was added to the lysate and incubated for another $6 \mathrm{~h}$, followed by high-speed centrifugation $(12,000 \mathrm{x} \mathrm{g})$ for $10 \mathrm{~min}$. Immune complexes were collected with protein G-agarose and washed three times with cell dissociation buffer. The washed beads were incubated with $15 \mu \mathrm{l}$ kinase buffer [250 $\mu \mathrm{M} \mathrm{ATP}, 1.4 \mu \mathrm{Ci}(\gamma$-32P) ATP, $20 \mathrm{mM}$ Tris- $\mathrm{HCl} \mathrm{pH} 7.5,5 \mathrm{mM} \mathrm{MgCl}, 1 \mathrm{mM}$ dithiothreitol and $100 \mu \mathrm{M}$ phosphate glycogen synthase peptide 2] at $30^{\circ} \mathrm{C}$ for $30 \mathrm{~min}$. The reaction was terminated by the addition of $12.5 \mu 1300 \mathrm{mmol} / 1$ phosphate. GSK-3 $\beta$ kinase activity was assayed using the Liquid Scintillation Counter (Beckman Coulter, Miami, FL, USA).

Statistical analysis. Intragroup differences in Timm scores were analyzed using the Kruskal-Wallis $\mathrm{H}$ test and intergroup differences were analyzed with a Mann-Whitney U test, followed by a Nemenyi test for pairwise comparison. The remaining indices for the difference between the PTZ and control group were performed with Student's t-test. The means of each group were compared using a one-way analysis of variance and then Fisher's least significant difference test for pairwise comparison. $\alpha=0.05$ was selected as the level of significance and $\mathrm{P}<0.05$ was considered to indicate a statistically significant difference. All statistical analyses were two-sided and were performed using the Statistical Package for the Social Sciences (SPSS), version 16.0 (SPSS, Inc., Chicago, IL, USA). 


\section{Results}

Behavioral outcomes. In each experimental group, prior to kindling, with the exception of one fatality in the 1 week group due to persistent generalized tonic-clonic seizure, seizure activity in the rats was only observed at grades 0-3. Following kindling in the experimental group, with the exception of one fatality in the 4-week group due to frequent seizures, the rats developed seizure activity at grades 3-5 following continuous PTZ injections for 18-22 days. The PTZ-treated rats were in accordance with the kindling criterion 26.1 \pm 1.6 days following PTZ injection. The PTZ-induced seizure activity usually occurred 5-10 min following injection, with a duration of 5-30 min. SRSs at grades 2-3 were detected in kindled rats as early as 23 days following PTZ injection. However, no epileptiform behavior was observed in the control rats.

Timm scores. Timm staining patterns in PTZ-treated rats differed significantly from those of the control rats. There was an increased distribution of Timm granules in the stratum pyramidale of the CA3 region at each time point in the PTZ group $(\mathrm{P}<0.05)$ (Fig. 1A and $\mathrm{C})$. In addition, the degree of MFS in the CA3 area progressed with the development of behavioral kindled seizures and peaked at 6 weeks. However, the Timm scores for the DG supragranular regions were 0-1 throughout the experiment in the PTZ group, with no significant difference compared with those of the control group ( $P>0.05$ ) (Fig. 1B and D). In addition, no significant difference was identified in the Timm scores for the CA3 area and the supragranular regions at each time-point within the control rats $(\mathrm{P}>0.05)$.

Expression and activity of GSK-3 $\beta$. The expression of GSK-3 $\beta$ mRNA and protein in the PTZ group increased markedly from 3 days to 2 weeks $(\mathrm{P}<0.01)$ and declined to control levels at 6 weeks (Fig. 2), whereas the expression of GSK-3 $\beta$ mRNA and protein was observed at various regions in the hippocampus of control rats, with no significant difference among the time-points. GSK-3 $\beta$ kinase activity increased in parallel with GSK-3 $\beta$ protein expression from day 3 in the PTZ group, reaching a peak at 2 weeks, declining from 4 weeks and finally returning to the control levels at 6 weeks. Conversely, there was no significant difference in GSK-3 $\beta$ activity in the frontal region between the PTZ and control groups. Furthermore, no significant changes were identified in the GSK-3 $\beta$ activity in the hippocampi of the control rats (Table I).

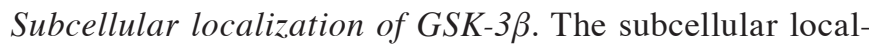
ization of GSK-3 $\beta$ changed markedly during the kindling process. The expression of GSK- $3 \beta$ mRNA and protein was observed in pyramidal cells in the CA3 area, CA1 area and in the granular cells in the DG of the control rat hippocampus, predominantly in the neuronal membranes and processes. However, in the PTZ group, GSK-3 $\beta$ translocated to the soma throughout kindling development, which was particularly notable 2 weeks following the initial PTZ injection, and the expression decreased to a low level in the soma at 6 weeks (Fig. 3).
A
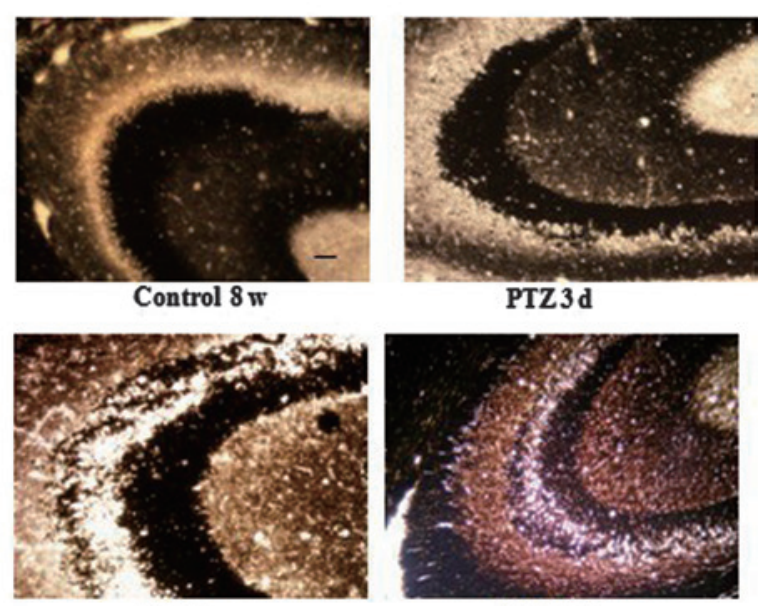

PTZ1 w

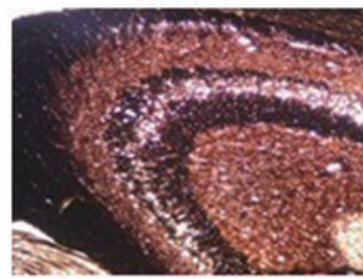

PTZ 4 w

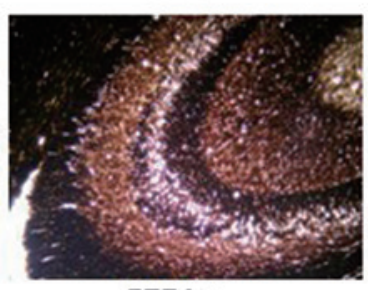

PTZ2 w

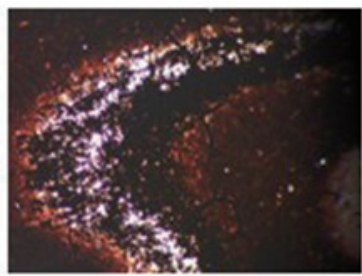

PTZ 6 w

B

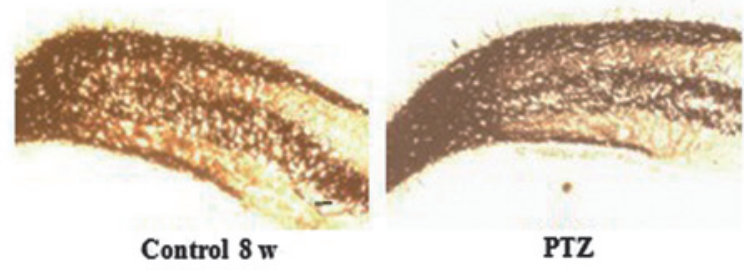

C

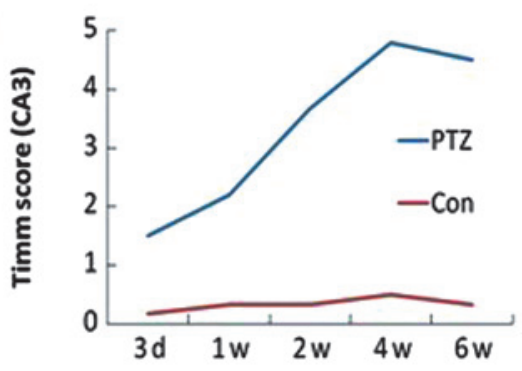

D

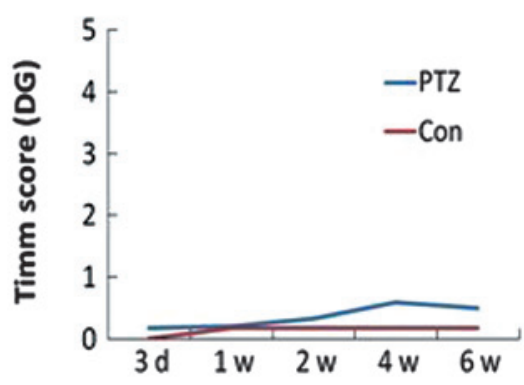

Figure 1. Progression of MFS in the hippocampus. (A) The intensity of Timm granules increased with the development of kindling in the CA3 region in the PTZ group $(\mathrm{P}<0.05)$. (B) No obvious MFS was observed in the DG supragranular regions in the control and PTZ groups at any time-point $(\mathrm{P}>0.05)$. Time-dependent changes of Timm scores in the (C) CA3 and (D) DG supragranular regions of the hippocampus, respectively. (Scale bars, $100 \mu \mathrm{m}$ ) MFS, mossy fibre sprouting; PTZ, pentylenetetrazole; con, control; DG, dentate gyrus. Original magnification, x100. 
A

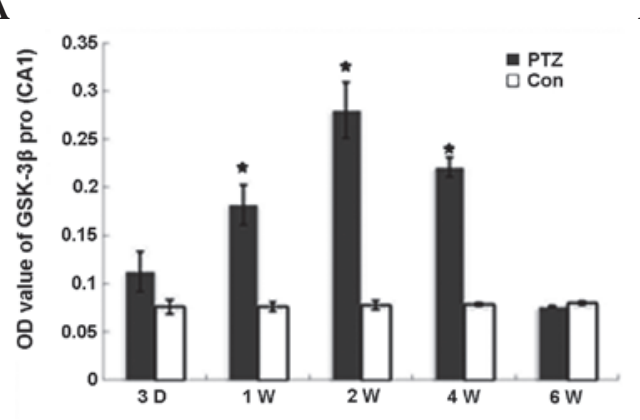

C

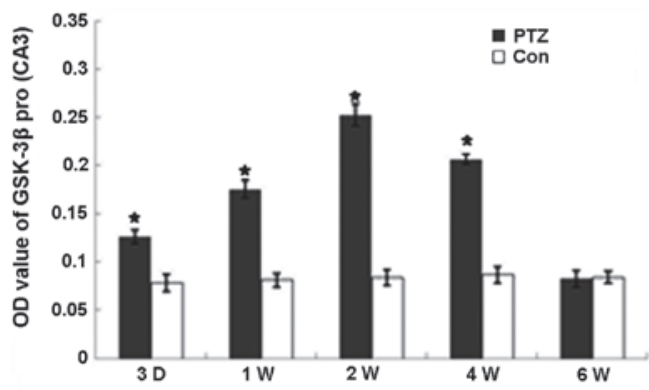

B

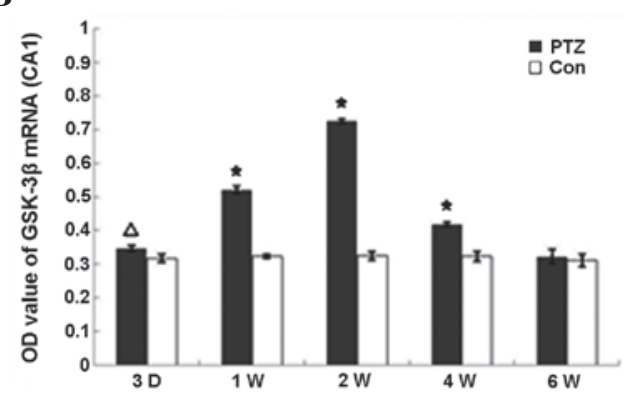

D

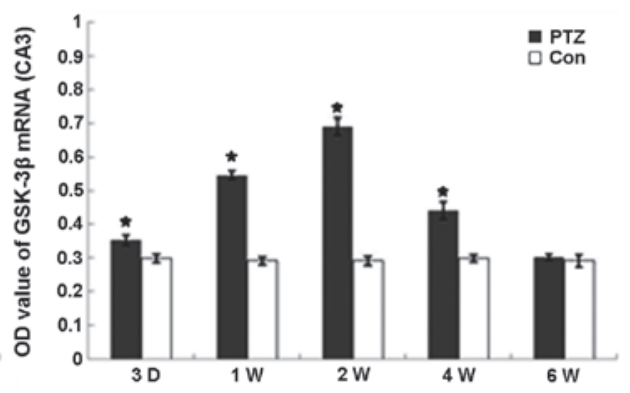

$\mathbf{E}$

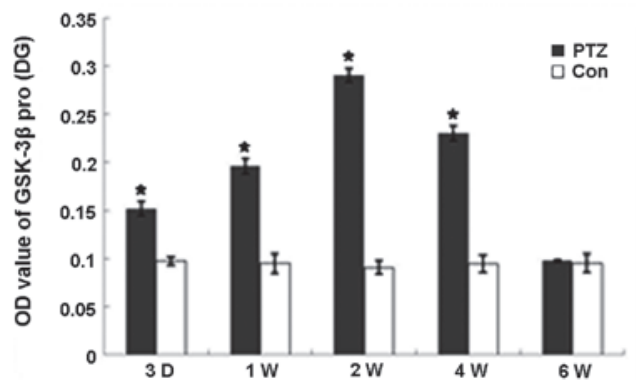

$\mathbf{F}$

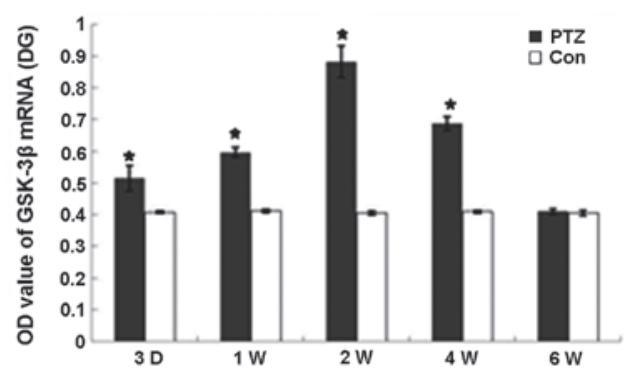

Figure 2. Quantitative analyses of GSK-3 $\beta$ protein and mRNA expression. GSK-3 $\beta$ protein expression increased from 3 days in the PTZ group, peaking significantly at 2 weeks, declining from 4 weeks and returning to control levels at 6 weeks in the (A) CA1, (C) CA3 and (E) DG regions. GSK-3 $\beta$ mRNA expression increased in parallel with GSK-3 $\beta$ protein in the (B) CA1, (D) CA3 and (F) DG regions. Data are presented as the mean $\pm \mathrm{SEM}$. ${ }^{*} \mathrm{P}<0.01$ and ${ }^{\Delta} \mathrm{P}<0.05$ compared with the control. GSK-3 $\beta$, glycogen synthase kinase-3 $\beta$; PTZ, pentylenetetrazole; con, control; DG, dentate gyrus.

\section{Discussion}

The present study demonstrated that as the degree of aberrant MFS increased, the severity of seizures and the amplitude and frequency of excitatory postsynaptic currents increased. MFS was observed prior to the occurrence of TLE and was increased following kindling, which suggested that repeated seizures aggravated MFS; however, it did not indicate that MFS was a consequence of SRS. Furthermore, MFS may not be the sole determinant of the onset of TLE, and other mechanisms, such as hilar ectopic dentate granule cells, may also be involved in epileptogenesis (15). An increased distribution of Timm granules was observed at the CA3 region, but not at the supragranular regions, which differs from that in the pilocarpine and kainic acid (KA) kindling models $(16,17)$ and is consistent with the results of a previous study (18). The difference in the distribution of Timm granules among the PTZ-kindling, pilocarpine and KA models may be attributed to the differences in the type and dose of the different convulsants and the severity of the induced seizures. Pilocarpine and KA may induce status epilepticus (SE), which leads to hippocampal neuronal death, particularly in the CA3 area. This study used moderate doses of PTZ to establish a kindling model in which SE rarely occurred. The extent of neuronal injuries caused by generalized tonic-clonic convulsions and SRS was less severe than that by SE. Regardless of the marginal injuries in the observed CA3 region and the hilar neurons, sprouted mossy fibers were able to locate sufficient post-synaptic target cells without returning to the DG supragranular regions.

GSK-3 $\beta$ is involved in numerous neuronal functions and affects neuronal polarity through undermining the structural stability of axons, regulating microtubule dynamics in growing axons, which leads to synaptic reorganization and the formation of recurrent excitatory circuits (19). Moreover, a study demonstrated that GSK-3 $\beta$ was able to hyperphosphorylate tau protein and may contribute to the pathogenesis of focal cortical dysplasia (FCD) in older patients. FCD is an important neurodevelopmental cause of refractory human epilepsy. However, thus far there have been no studies regarding a correlation between GSK-3 $\beta$ and MFS (20). In the 
Table I. Quantitative analyses of GSK-3 $\beta$ activity (P-32 counts per minute value).

\begin{tabular}{|c|c|c|c|c|}
\hline \multirow[b]{3}{*}{ Group } & \multicolumn{4}{|c|}{ GSK-3 $\beta$ activity } \\
\hline & \multicolumn{2}{|c|}{ Hippocampus } & \multicolumn{2}{|c|}{ Frontal region } \\
\hline & PTZ & Control & PTZ & Control \\
\hline 3 day & $5886.47 \pm 252.71^{\mathrm{a}}$ & $2013.40 \pm 130.31$ & $2074.90 \pm 214.80$ & $2073.55 \pm 158.26$ \\
\hline 1 week & $7789.87 \pm 334.51^{\mathrm{a}}$ & $2011.53 \pm 163.37$ & $2158.38 \pm 196.83$ & $2015.13 \pm 156.15$ \\
\hline 2 weeks & $11503.55 \pm 1527.55^{a}$ & $2061.42 \pm 203.47$ & $2250.27 \pm 266.08$ & $2018.53 \pm 156.66$ \\
\hline 4 weeks & $5822.15 \pm 488.93^{\mathrm{a}}$ & $2065.76 \pm 191.51$ & $2115.87 \pm 250.96$ & $1967.23 \pm 136.75$ \\
\hline 6 weeks & $2142.85 \pm 129.34$ & $2101.73 \pm 195.04$ & $2078.28 \pm 221.22$ & $2014.38 \pm 105.88$ \\
\hline
\end{tabular}

Quantitative analyses of GSK-3 $\beta$ activity in the hippocampus and frontal region. Data are presented as the mean \pm SEM. Groups were separated by the time of sacrifice following the initial injection of PTZ. ${ }^{a} \mathrm{P}<0.01$, vs. the control. PTZ, pentylenetatrazole.

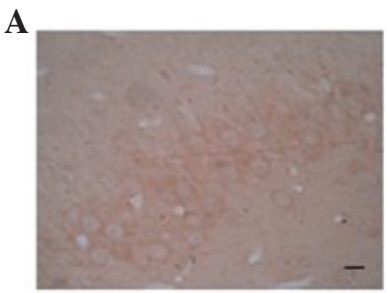

Control

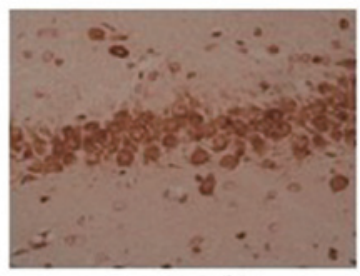

Ptz 2W

B

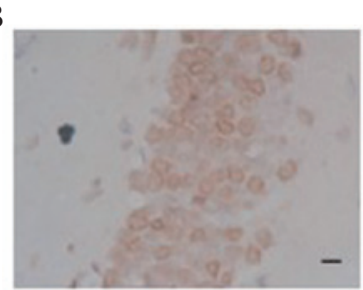

Control

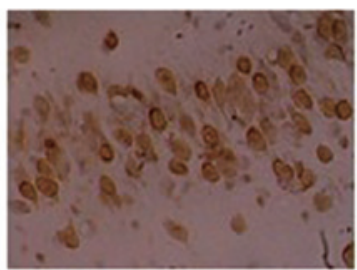

Ptz 2W

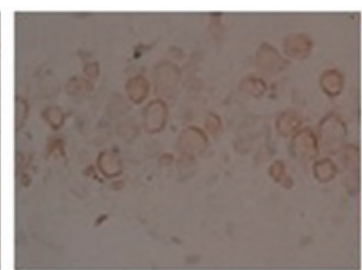

Ptz 3D

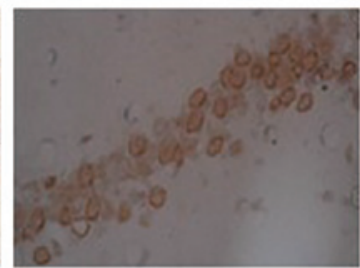

Ptz 4W

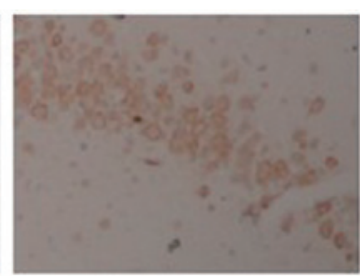

Ptz 3D

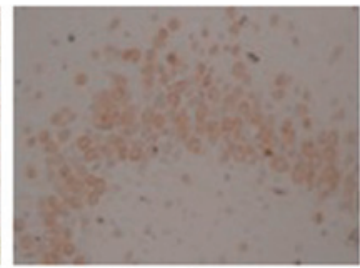

Ptz 4W

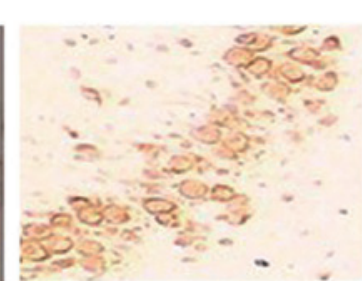

Ptz 1W

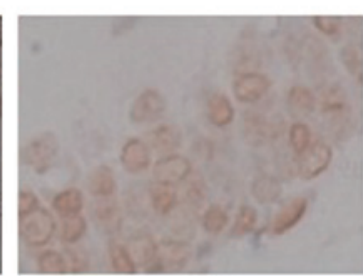

Ptz 6W

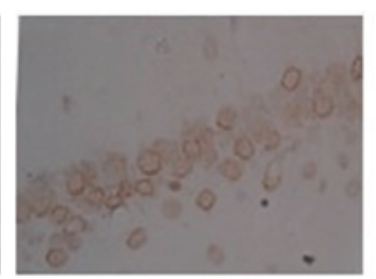

Ptz 1W

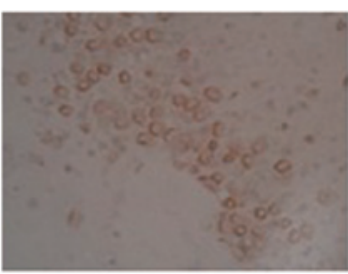

Ptz 6W

Figure 3. Immunohistochemistry and in situ hybridization localization of GSK-3 $\beta$ (A) protein and (B) mRNA in the CA3 area of control rats and PTZ-treated rats. GSK-3 $\beta$ protein and mRNA translocated from neuronal membranes and processes to the soma throughout kindling development, which was particularly notable in the 2 weeks following the initial PTZ injection. The expression became low in the soma at 6 weeks. (Scale bar=50 $\mu \mathrm{m}$ ). GSK-3 $\beta$, glycogen synthase kinase; PTZ, pentylenetetrazole. Original magnification, x200.

present study, the expression of GSK-3 $\beta$ mRNA and protein was increased in the DG, however, no MFS was observed in this area. This does not indicate that GSK-3 $\beta$ does not exhibit a correlation with MFS, as a previous study determined that in the PTZ-kindling model, hippocampal neuronal death in the DG area was more severe than in the CA3 area (13), 
therefore sprouted mossy fibers were not able to locate sufficient post-synaptic target cells and turned back to the inner molecular layer of the DG. In a previous study, it was demonstrated that tau protein and its phosphorylation at Ser202 increased significantly in the PTZ group (21). Furthermore, in the present study, the expression of GSK-3 $\beta$ mRNA and protein, as well as its activity, also increased significantly from 3 days to 4 weeks in the PTZ group, which was correlated with an increase in phosphorylated tau protein. These results suggested that GSK-3 $\beta$ may be involved in MFS in the kindling rat hippocampus through the phosphorylation of tau.

The mechanisms underlying the correlation between GSK-3 $\beta$ and MFS remain unknown. A study demonstrated that GSK-3 $\beta$ is abundant in soma when its activity is high, whereas it is expressed in axons when the activity is low (19). Results also suggest that in the PTZ group, GSK-3 $\beta$ translocated from the axon to soma during the progression of MFS. Tau is synthesized and subsequently phosphorylated within the cell body; however, in the proximal axonal process, such as within growing neurons, it is dephosphorylated by phosphatases during axonal transport, resulting in the stabilization of the microtubule cytoskeleton. Furthermore, excessive aggregation of GSK-3 $\beta$ and phosphorylated tau in soma exhibited high cytotoxicity and resulted in apoptosis and necrosis $(22,23)$. This may be due to an alternate mechanism of MFS caused by GSK-3 $\beta$. Increased expression and activity of GSK-3 $\beta$ led to the phosphorylation of tau protein, which subsequently induced MFS through reducing its microtubule binding ability and promoting microtubule assembly function.

In conclusion, the present study demonstrated a correlation between MFS and GSK-3 $\beta$. GSK-3 $\beta$ may be involved in the progression of MFS through abnormal phosphorylation of tau protein. However, the importance and specific mechanisms of GSK in the formation of MFS were not determined. GSK is not the only enzyme that regulates tau protein phosphorylation and MFS may not be the sole determinant of the onset of TLE. Further studies are required that modulate the expression and activity of GSK-3 $\beta$ in mossy fiber sprouting in the PTZ-kindling model, and assess whether there are corresponding changes in the level of tau protein phosphorylation, MFS formation and the severity of epilepsy. Understanding the involvement of GSK-3 $\beta$ in MFS may lead to novel therapeutic interventions, and therefore ameliorate epileptogenic network dysfunction and associated morbidities.

\section{References}

1. Kuo LW, Lee CY, Chen JH, Wedeen VJ, Chen CC, Liou HH and Tseng WY: Mossy fiber sprouting in pilocarpine-induced status epilepticus rat hippocampus: a correlative study of diffusion spectrum imaging and histology. NeuroImage 41: 789-800, 2008.

2. Andrade-Valença LP, Valença MM, Velasco TR, Carlotti CG Jr, Assirati JA, Galvis-Alonso OY, Neder L, Cendes F and Leite JP: Mesial temporal lobe epilepsy clinical and neuropathologic findings of familial and sporadic forms. Epilepsia 6: 1046-1054, 2008.

3. Sutula TP and Dudek FE: Unmasking recurrent excitation generated by mossy fiber sprouting in the epileptic dentate gyrus: an emergent property of a complex system. Prog Brain Res 163 541-563, 2007.
4. Longo BM and Mello LE: Effect of long-term spontaneous recurrent seizures or reinduction of status epilepticus on the development of supragranular mossy fiber sprouting. Epilepsy Res 36: 233-241, 1999.

5. Johnson GV and Stoothoff WH: Tau phosphorylation in neuronal cell function and dysfunction. J Cell Sci 117: 5721-5729, 2004.

6. Merrick SE, Demoise DC and Lee VM: Site-specific dephosphorylation of tau protein at Ser202/Thr205 in response to microtubule depolymerization in cultured human neurons involves protein phosphatase 2A. J Biol Chem 271: 5589-5594, 1996.

7. Pollard H,Khrestchatisky M, Moreau J,Ben-Ari Y and Represa A: Correlation between reactive sprouting and microtubule protein expression in epileptic hippocampus. Neuroscience 61: 773-787, 1994.

8. Palmio J, Suhonen J, Keränen T, Hulkkonen J, Peltola J and Pirttilä T: Cerebrospinal fluid tau as a marker of neuronal damage after epileptic seizure. Seizure 18: 474-477, 2009.

9. Plattner F, Angelo M and Giese KP: The roles of cyclin-dependent kinase 5 and glycogen synthase kinase 3 in tau hyperphosphorylation. J Biol Chem 281: 25457-25465, 2006.

10. Yeste-Velasco M, Folch J, Trullàs R, Abad MA, Enguita M, Pallàs M and Camins A: Glycogen synthase kinase- 3 is involved in the regulation of the cell cycle in cerebellar granule cells. Neuropharmacology 53: 295-307, 2007.

11. Zhou FQ and Snider WD: Cell biology. GSK-3 $\beta$ and microtubule assembly in axons. Science 308: 211-214, 2005.

12. National Institues of Health: Guide for the care and use of laboratory animals. The National Academies Press. Washington, D.C., 1996.

13. Racine RJ: Modification of seizure activity by electrical stimulation. II. Motor seizure. Electroencephalogr Clin Neurophysiol 32: 281-294, 1974.

14. Sogawa Y, Monokoshi M, Silveira DC, Cha BH, Cilio MR, McCabe BK, Liu X, Hu Y and Holmes GL: Timing of cognitive deficits following neonatal seizures: relationship to histological changes in the hippocampus. Brain Res Dev Brain Res 131: 73-83, 2001.

15. Pierce JP,Melton J,Punsoni M,McCloskey DP and Scharfman HE: Mossy fibers are the primary source of afferent input to ectopic granule cells that are born after pilocarpine-induced seizures. Exp Neurol 196: 316-331, 2005.

16. Holmes GL, Sarkisian M, Ben-Ari Y and Chevassus-Au-Louis N: Mossy fiber sprouting after recurrent seizures during early development in rats. J Comp Neurol 404: 537-553, 1999.

17. Cross DJ and Cavazos JE: Synaptic reorganization in subiculum and CA3 after early-life status epilepticus in the kainic acid rat model. Epilepsy Res 73: 156-165, 2007.

18. Tian FF, Zeng C, Guo TH, Chen Y, Chen JM, Ma YF, Fang J, Cai XF, Li FR, Wang XH, et al: Mossy fiber sprouting, hippocampal damage and spontaneous recurrent seizures in pentylenetetrazole kindling rat model. Acta Neurol Belg 109: 298-304, 2009.

19. Jiang H, Guo W, Liang X and Rao Y: Both the establishment and the maintenance of neuronal polarity require active mechanisms: critical roles of GSK-3 $\beta$ and its upstream regulators. Cell 120: 123-135, 2005.

20. Sen A, Thom M, Martinian L, Harding B, Cross JH, Nikolic M and Sisodiya SM: Pathological tau tangles localize to focal cortical dysplasia in older patients. Epilepsia 48: 1447-1454, 2007.

21. Tian FF, Zeng C, Ma YF, Guo TH, Chen JM, Chen Y, Cai XF, Li FR, Wang XH, Huang WJ and Wang YZ: Potential roles of $\mathrm{Cdk} 5 / \mathrm{p} 35$ and tau protein in hippocampal mossy fiber sprouting in the PTZ kindling model. Clin Lab 56: 127-136, 2010.

22. Linseman DA, Butts BD, Precht TA, Phelps RA, Le SS, Laessig TA, Bouchard RJ, Florez-McClure ML and Heidenreich KA: Glycogen synthase kinase-3beta phosphorylates Bax and promotes its mitochondrial localization during neuronal apoptosis. J Neurosci 24: 9993-10002, 2004.

23. Chen L, Wei Y, Wang X and He R: D-Ribosylated Tau forms globular aggregates with high cytotoxicity. Cell Mol Life Sci 66: 2559-2571, 2009. 